Casos Clínicos

Arch. Esp. Urol., 60, 1 (81-83), 2007

\section{TUMOR TESTICULAR METACRONICO SECUNDARIO A CARCINOMA VESICAL INFILTRANTE.}

Francisco Javier Vicente Prados, José Luís Rosales Leal Beatriz Honrubia Vilchez, Antonio Fernández Sánchez, Fernando Vázquez Alonso, Manrique Pascual Geler Antonio Martínez Morcillo, Francisco Rodríguez Herrera, Eduardo Espejo Maldonado, José Manuel Cozar Olmo y Miguel Tallada Buñuel.

Servicio de Urología del Hospital Universitario de Granada. España.

Resumen.- OBJETIVO: Presentar un caso raro de metástasis testicular secundaria a carcinoma urotelial infiltrante años después de practicada cirugía radical.

MÉTODOS: Exposición del caso clínico: paciente de 71 años sometido a cistoprostatectomía radical con uretrectomía por tumor vesical infiltrante. A los siete años debuta con dolor y aumento del tamaño testicular derecho. Se le practicó orquiectomía por vía inguinal siendo diagnosticado de metástasis testicular de carcinoma vesical de alto grado. y revisión de la literatura publicada al respecto.
RESULTADOS: Supervivencia libre de enfermedad a los 12 meses de la orquiectomía.

CONCLUSIONES: El tumor testicular metastático excluyendo leucemias y linfomas es extremadamente raro. La presencia de metástasis testiculares supone una diseminación metastásica a otros niveles y por ello la Quimioterapia podría mejorar el pronóstico.

Palabras clave: Tumor vesical infiltrante. Metástasis testicular. Tratamiento quirúrgico.

Summary.- OBJECTIVE: To report a rare case of testicular metastasis secondary to an infiltrative transitional cell carcinoma years after radical surgery.

METHODS: Case Report: 71-year-old male patient with history of infiltrative bladder tumor, status post radical cystoprostatectomy with urethrectomy. Seven years after surgery he presents with pain and swelling in the right testicle. Inguinal orchyectomy was carried out with the pathologic diagnosis of testicular metastasis of a highgrade transitional cell carcinoma. We perform a bibliographic review.

RESULTS: The patient is disease-free twelve months after orchyectomy.

CONCLUSIONS: Apart from leukemia and lymphoma, testicular metastases are extremely rare. The existence of testicular metastases means a metastatic dissemination to other organs, therefore chemotherapy could improve prognosis.

Keywords: Infiltrative bladder tumor. Testicular metastasis.

\section{INTRODUCCIÓN}

Presentamos un caso de metástasis testicular metacrónica a los 7 años de cistoprostatectomía y uretrectomía radical con derivación urinaria tipo Bricker-Wallace II por tumor vesical infiltrante.

\section{CASO CLÍNICO}

Paciente de 71 años de edad que consulta por dolor y aumento del tamaño testicular derecho. En la exploración física se palpa un testículo derecho aumentado de tamaño y consistencia, sin signos inflamatorios. Se le realiza estudio ecográfico donde se aprecia en el testículo derecho una lesión focal hipoecogénica con respecto al parénquima adyacente de $27 \times 22 \mathrm{~mm}$ de diámetro con algunos septos finos y pequeñas calcificaciones de su pared y que desde el punto de vista ecográfico podría corresponder con un tumor epidermoide 


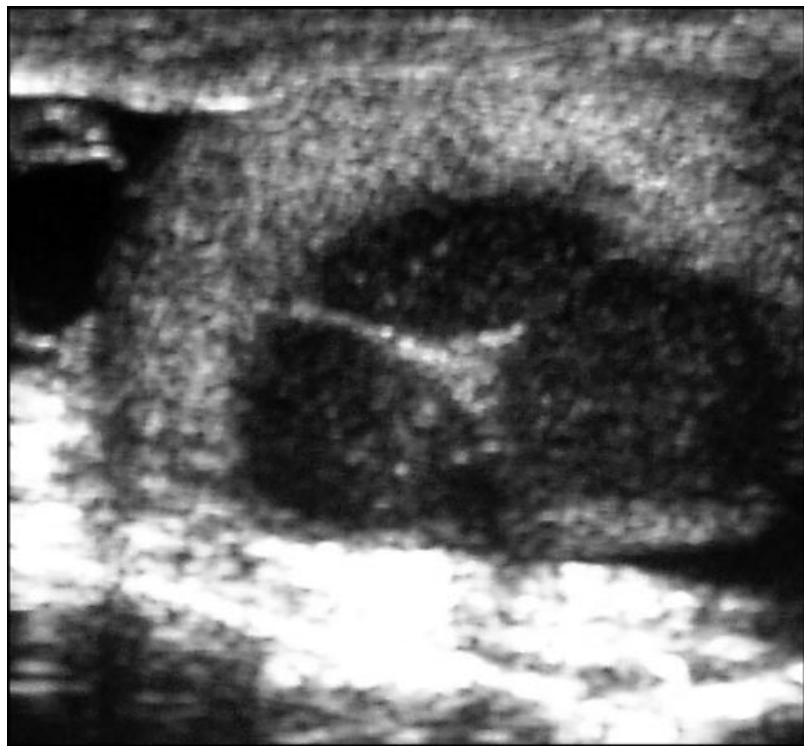

FIGURA 1. Imagen ecográfica: lesión focal hipoecogénica con respecto al parénquima con finos y pequeñas calcificaciones compatible con tumor epidermoide.

(Figura 1). Los marcadores tumorales ( $\beta \mathrm{HCG}$ y $\alpha \mathrm{FP})$ son normales.

Entre los antecedentes personales del paciente destaca el hecho de que hacía 7 años había sido fue intervenido de un tumor vesical infiltrante. Se realizó cistoprostatectomía radical con uretrectomía, linfadenectomía ileo-obturatriz bilateral y derivación urinaria tipo Bricker-Wallace II. La anatomía patológica fue de carcinoma papilar urotelial de alto grado con invasión de la serosa y de la uretra prostática (pT4). Linfadenitis reaccional en las 18 adenopatías aisladas. Se le propuso tratamiento adyuvante con quimioterapia que rechazó.

El paciente fue seguido en consulta de forma semestral durante los 5 primeros años y anual con posterioridad. Todas las exploraciones analíticas y de imagen fueron negativas encontrándose libre de enfermedad tumoral hasta el diagnóstico de la lesión testicular.

Con el diagnóstico de tumor testicular derecho se intervino practicándose orquiectomía derecha por vía inguinal. El diagnóstico anatomopatológico fue de metástasis de carcinoma papilar urotelial de alto grado. Epidídimo y cordón libres de elementos tumorales (Figura 2).

Una vez conocido el diagnostico se le completa el estudio de extensión con TAC torazo-abdominal donde no se aprecian adenopatías ni metástasis a distancia. El rastreo óseo también es negativo. Se le propone de nuevo tratamiento adyuvante con QT que es rechazado.

En la actualidad al año de la intervención está asintomático y libre de enfermedad.
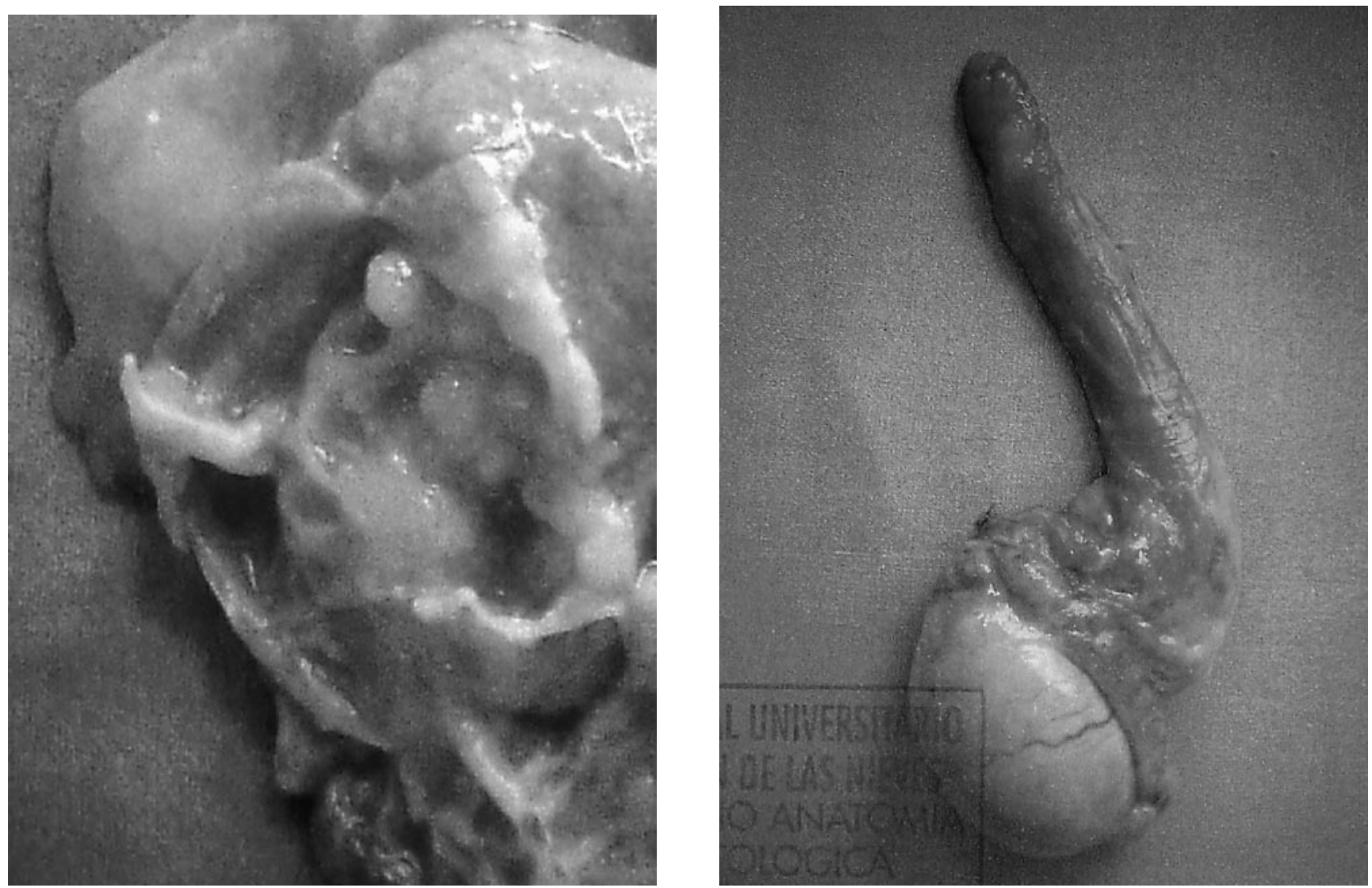

FIGURA 2. Imagen macroscópica de la tumoración. 


\section{DISCUSIÓN}

El tumor testicular metastático excluyendo leucemias y linfomas es extremadamente raro.

Las metástasis del carcinoma vesical infiltrante en testículo también son excepcionales y en la literatura no hay recogidos más de 6 casos (1)

Es clásica la serie de Pienkos y Jablokow donde encuentran sólo 15 tumores testiculares metastáticos de origen prostático y pulmonar en una serie de 24.000 autopsia (2).La incidencia de metástasis de carcinoma en testículo, en largas series revisadas de autopsias, se sitúan en un $0,8-2,3 \%$ de los tumores testiculares detectados (3).

También se han publicados metástasis testiculares de tumores renales (4), tumores del tracto gastrointestinal (colón, yeyuno y páncreas) (5) y melanomas (6). Las metástasis procedentes de tumores vesicales infiltrantes son excepcionales.

En ocasiones es diagnóstcado de manera incidental al realizar la orquiectomía bilateral como tratamiento de carcinoma de próstata metastásico. $(1,2,7)$.

Acontecen en pacientes de edad avanzada 71 años en nuestro caso) y la afectación bilateral sólo se ha descrito en tumores de próstata y en 1 caso de retinoblastoma (8).

En los casos secundarios a carcinoma de próstata, se piensa en la diseminación a través de los deferentes. Hanash ha encontrado 9 casos de asociación de carcinoma de próstata y metástasis en cordón espermático lo que apoya esta teoría (9).

En las metástasis a partir de carcinomas del riñón izquierdo la vía hematógena a través de la vena espermática es la más aceptada (10).

La presencia de metástasis testiculares conlleva un pobre pronóstico, ya que hemos de esperar la aparición de diseminación metastásica a otros niveles y por ello la quimioterapia podría mejorar el pronóstico, aunque en el caso que presentamos el paciente está libre de enfermedad al año sin quimioterapia.

\section{CONCLUSIONES}

El tumor testicular metastático excluyendo leucemias y linfomas es extremadamente raro. La presencia de metástasis testiculares supone una diseminación metastásica a otros niveles y por ello la Quimioterapia podría mejorar el pronóstico.

\section{BIBLIOGRAFÍA y LECTURAS RECOMENDADAS ( ${ }^{*}$ lectura de interés $y^{* *}$ lectura fundamental)}

*1. BEARDO, P.; MANASIA, P.: "Rare secondary carcinoma from bladder to testis". Urol. Int.;68:204. 2002.

2. PIENKOS, E.J.; JABLOKOW, V.R.: "Secundary testicular tumors". Cancer; 30:481. 1972.

*3. SHEYASKUMAR, R.P.: "Metastasic cancer to the testes:A report of 20 cases and review of the literature”. J. Urol.;142:1003. 1989.

4. TALERMAN, A.; KNIESTED, W.F.: "Testicular tumors as the first manifestation of the renal carcinoma”. J. Urol.;118:489. 1977.

5. JUBELIRER, S.J.: "Metastatic colon carcinoma to the testis: Case report and review of the literature". J. Surg. Oncol.:32:22. 1986.

*6. CRICCO ROBERT, P. y KANZARI STANLEY, J.: "Secondary testicular tumors". J.Urol; 118: 489. 1977.

*7. PRICE, E.B. JR.; MASTOFI, F.K.: "Secondary carcinoma of the testis". Cancer 10:592. 1957.

**8. HANASH, K.A.; CARNEY, J.A.; y KELALIS, P.P.: "Metastatic tumours to the testicle: routes of metastasis". J. Urol.; 102: 465. 1969.

**9. HANASH, K.A.: "Metastatic tumours to the testicle”. Prog Clin Biol Res;203:61. 1985.

10. DIECKMAN, K.P.; DÜE, W.; LOY, V.: "Intrascrotal metastasis of renal cell carcinoma". Eur. Urol.; 15: 297. 1988. 